\title{
Behaviour of Waler Retaining System on Sheet Piles using Finite Element Method
}

\author{
Ammar Jalil Almosawi, Anis A. Mohamad-Ali, David A. M Jawad \\ University of Kufa, Iraq
}

\begin{abstract}
In this paper, a truss retaining system on a cantilever sheet piles in a 300 meter length berth was studied using two dimensional plain strain analysis. The analysis of the soil continuum under the effect of active and passive pressure in addition to the cyclic load effect was extended by using the finite element method with the aid of the software Autodesk FEM ROBOT 2019. The most common analyses, designs and properties of such load cases were reviewed. The soil continuum was modeled using 15 node triangular element and the stress concentration for all the nodes was analyzed. The behavior of truss retaining system under the effect of active, passive and cyclic loads are predicted in this study by using FEM ROBOT software 2019.
\end{abstract}

\section{Keywords: - Sheet piles, truss retaining system, FEM, ROBOT program}

\section{INTRODUCTION}

Sheet piles are of the most important retaining systems. Behavior of the sheet piles depends mainly on the active load, the passive load and the way of retaining system. A truss retaining system with a continuous waling beam connected to sheet pile subjected to several load types like active, passive and cyclic load was analyzed in the present work. Usually the waler beam is connected to the tie rods in which the waler beam behaves as continuous walling beam and the tie rods points represent the reactions of the continuous waler beam. In the present work a truss supports the waler beam in a cantilever sheet piles. However, the key of our motivation is to look for an approach that can be employed to avoid excavation problems during the tie rods installing along the port length.

Reference is made to several papers that have discussed various types of supporting systems and their construction, for example, Chang de Young (2007), Bogdan Rymsza (2008), Leila Eskandari (2011), and David Baxter, (2016) [4], Engineers EDGE (2018). A truss system is installed in Xz-plane with I sections properties of (W28X16). (U-channels U25X18) were installed as bracing in $\mathrm{xz}, \mathrm{yz}$ and $\mathrm{xy}$-planes for the truss. The layout of the truss is as shown in Figure (1). The effect of using a truss as supporting system instead of tie rods was tested using the ROBOT software 2019 program in order to study the stress concentration behavior, bending moment behavior and the effect of truss supporting instead of tie rods.

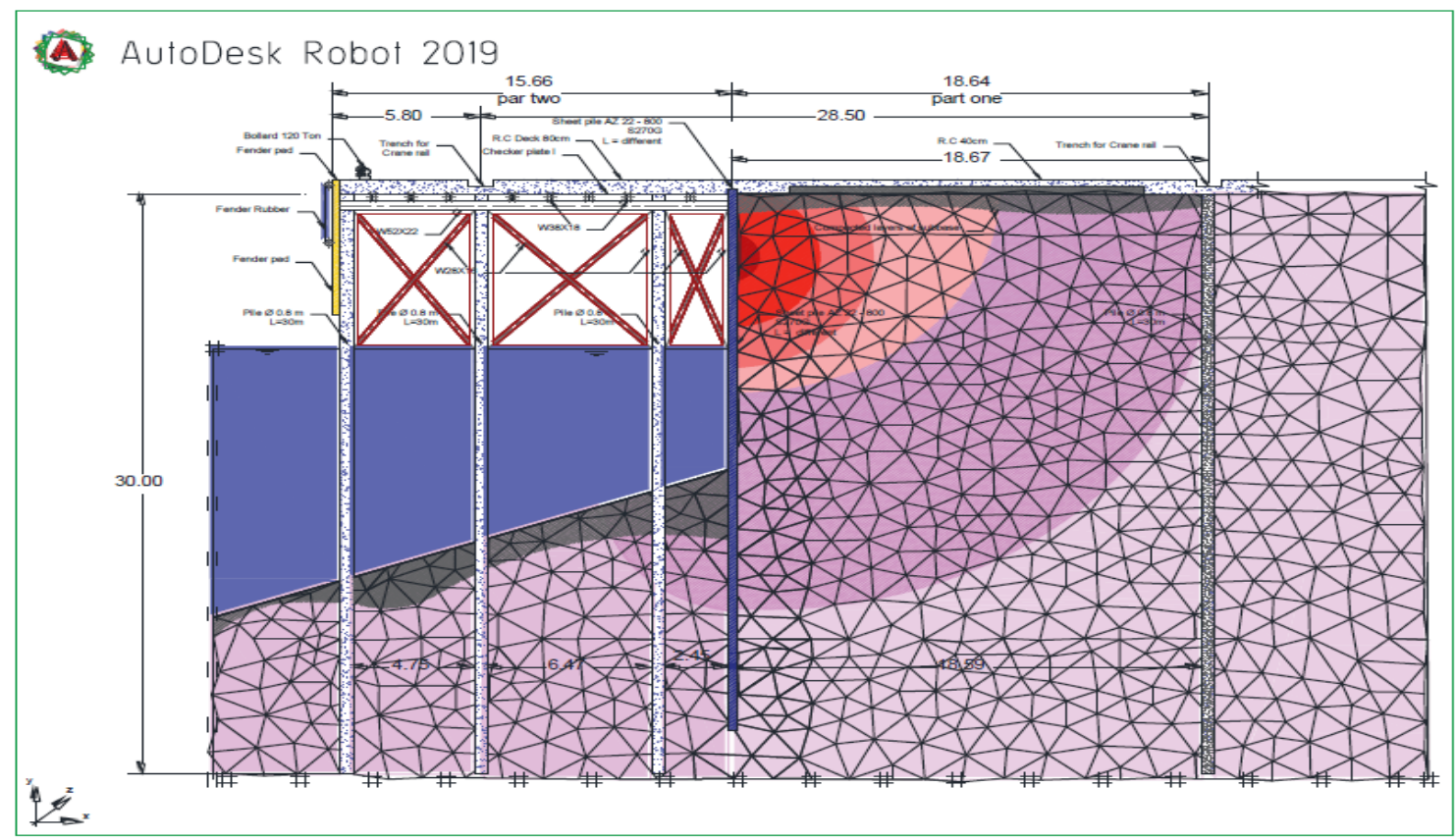

Figure (1) Side view of truss system retaining structure

Figure (1) shows a side view section of a berth 300 meter long with three lines of drive piles along the port. Figure (2) shows top view of the port with the located waler beam in front of the supporting truss. 


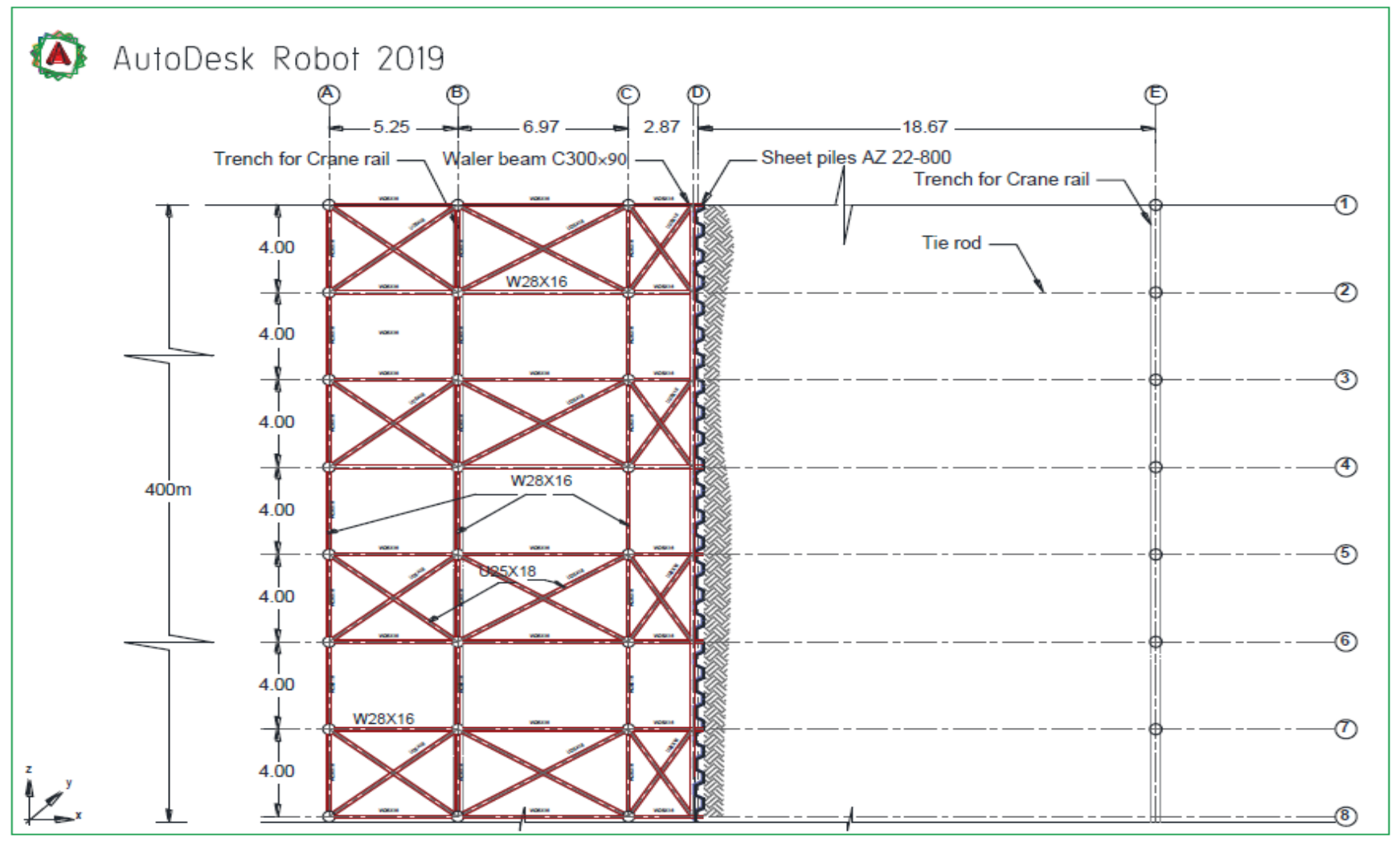

Figure (2) Top view of truss system retaining structure

\section{SITE DESCRIPTION}

\subsection{Layout of the structure}

A berth of 300 meter long has two main parts, land part $(18.64 \mathrm{~m})$ length and sea part $(15.66 \mathrm{~m})$ was retained by a $30 \mathrm{~m}$ sheet pile (AZ 22 800) supported by waler beam (double back to back channels C300x90), the waler beam is supported by a truss with specific properties installed in two directions ( $\mathrm{x}-\mathrm{z}$ plane) between the driven piles as shown in Figure (1) instead of tie rod system in order to retain the active load pressure from the land part and any other load types like crane load in addition to wave loads or cyclic loads due to ship impact from the sea side. The reinforced concrete deck provides a partial anchoring system throughout the shear connecters welded on the sheet piles tip connected to the deck reinforcement.

\subsection{Load application methodology}

The effect of cyclic load on the behavior of waler beam is shown in Table (1), at each cycle there were two cases, the loading case and the unloading case, and this may give an overall view for the behavior of the continuous waler beam in order to conclude the proper results. The cyclic load applied on the sheet piles comes from the repeated sea waves or from ships impact and was taken into account as a cyclic load effect in the software input data. The cyclic load is not constant it is transmitted as cumulative waves acting on the sheet piles, then transmitted directly to the continuous waler beam. The values of the cyclic load [P] were ranged from $\left(10.8-347.7 \mathrm{kN} / \mathrm{m}^{2} /\right.$ cycle $)$ as the minimum cyclic load recorded in the port was $\left(10 \mathrm{kN} / \mathrm{m}^{2} /\right.$ cycle $)$ and the maximum cyclic load at failure was $\left(365 \mathrm{kN} / \mathrm{m}^{2} /\right.$ cycle $)$.

The problem has been considered as plane strain problem so in order to improve the behavior of the waler reaction points, under the effect of cyclic load pressure it is required to analyze the results from tables by using zero order Hermite finite element polynomial function for 5 nodes element depending on the cubic equation function for plane strain analysis of continuous waler beam under the effect of cyclic load in finite element method in order to investigate the displacement of waler beam under cyclic load effect. The equivalent axial displacement for all load cases as shown from the following Hermite FEM equations (1-1) to (13) $[5]$

$$
u(z)=a_{1}+a_{2} z+a_{3} z^{2}+a_{4} z^{3}
$$

The constants $a_{1}, a_{2}, a_{3}$ and $a_{4}$ can be found by applying the boundary conditions;

$$
\delta_{i}=\sum_{i=1}^{5} \sum_{k=1}^{5} H_{0 i}^{5} \delta_{0 k}^{3}
$$


The finite element simulation for the transverse deformations of each node will be:

$$
\delta_{*}=\frac{\delta_{\text {middle at }(+0.1 p)}+\delta_{\text {middle at }(-0.1 p)}}{2}
$$

Where $[\mathrm{N}]$ is the shape functions for each node given by:

$$
v(z)=[N] \vec{q}
$$

$$
[N]=\left[\begin{array}{llll}
N_{1} & N_{2} & N_{3} & N_{4}
\end{array}\right]
$$

The nodal deformations of the continuous waler beam element are shown in the Figure (4). The shape functions of the nodal deformations are calculated from equations (1.6 To 1.7) are as follows;

$$
\begin{aligned}
& N_{1}(z)=\frac{2 z^{3}-3 / z^{2}+l^{3}}{l^{3}} \\
& N_{2}(z)=\frac{z^{3}-2 / z^{2}+l^{2} z}{l^{2}} \\
& N_{3}(z)=\frac{-\left(2 z^{3}-3 / z^{2}\right)}{l^{3}} \\
& N_{4}(z)=\frac{z^{3}-l z^{2}}{l^{2}}
\end{aligned}
$$

And the matrix of equivalent nodal displacement for the continuous waler beam element;

$$
\vec{q}=\left[\begin{array}{l}
q_{1} \\
q_{2} \\
q_{3} \\
q_{4}
\end{array}\right]
$$

The finite element method and according to simple beam theory, "plane sections of the beam remain plane after deformation" and hence the axial displacement $(u)$ due to the transverse displacement $(v)$ can be expressed as it is shown in Figure (3);

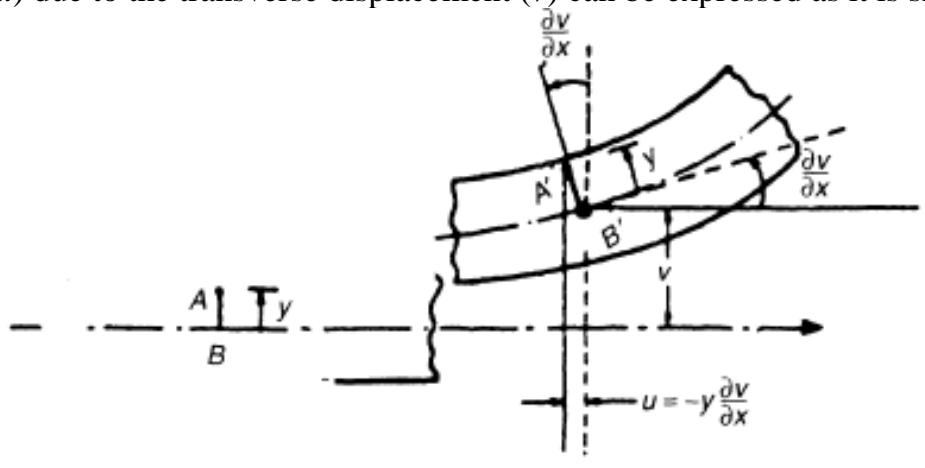

Figure (3) Transverse displacement for continuous beam element [1]

The relation between the axial and the transverse deformation is shown in equation (1.10):

$$
u=-y \frac{\partial v}{\partial x}
$$

Where y represents the distance from the neutral axis of the distorted continuous waler beam. While the axial strain is given by;

$$
\epsilon_{x x}=\frac{\partial u}{\partial x}=-y \frac{\partial^{2} y}{\partial x^{2}}=[R] \vec{q}
$$

If the nodal displacements of the element, $q_{1}, q_{2}, q_{3}$ and $q_{4}$ are known, the stress distribution in the element, $\sigma_{x x}$ can be found as

$$
\sigma_{x x}=\sigma_{x x}(x, y)=E \varepsilon_{x x}=[E][B] \vec{q}
$$

Where $\sigma_{x x}(x, y)$ represents the stress in the element at a point located at a specific distance from the origin (in horizontal direction from the left node) and from the neutral axis (in the vertical direction).

Where $[R]$ is given by;

$$
[\mathrm{R}]=-\frac{y}{l^{3}}\{(12 x-6 l) \quad l(6 x-4 l)-(12 x-6 l) \quad l(6 x-2 l)\}
$$

Using the equations above with $[\mathrm{D}]=[\mathrm{E}]$, the stiffness matrix can be found as; $[6]$

Where:

$$
\begin{gathered}
{\left[k^{(e)}\right]=\iiint_{V^{(e)}}[R]^{T}[D][R] d V=E \int_{0}^{l} d x \iint_{A}[R]^{T}[R] d A} \\
=k_{a}\left[\begin{array}{cccc}
12 & 6 l & -12 & 6 l \\
6 l & 4 l^{2} & -6 l & 2 l^{2} \\
-12 & -6 l & 12 & -6 l \\
6 l & 2 l^{2} & -6 l & 4 l^{2}
\end{array}\right]
\end{gathered}
$$

$k_{a}$ : is to be determined as modulus of subgrade reaction in the contact area

$I_{z z}=\iint_{A} y^{2} d A$ Is the area moment of inertia of the cross section about the $\mathrm{z}$ axis. Noting that the nodal interpolation functions $N,(x)$ are the same as the first-order Hermite polynomials. 
Many approaches exists in the finite element method to determine the contact area and the [k] matrix, which include the RayleighRitz approach, variational or method of weighted residual which depends on scaling down the powers of the equations in order to find the constants.

The theory of plane strain is applied for bodies that are long like long pipes as mentioned previously and whose geometry and loading do not vary significantly in the longitudinal direction. Therefore the analysis of sheet piling, dams, cylinders, and retaining walls use the assumption of plane strain. In plane strain distribution, it is assumed that $\partial \mathrm{w} / \partial z=0$ at every cross section. Here, the dependent variables are assumed to be functions of only the $\mathrm{x}$ and $\mathrm{y}$ coordinates provided. We consider a cross section of the body away from the ends, in this case the two dimensional stress-strain relations given by:

Where,

$$
\vec{\varepsilon}=[C] \vec{\sigma}+\overrightarrow{\varepsilon_{\circ}}
$$

Then,

$$
\begin{aligned}
\vec{\varepsilon} & =\left\{\begin{array}{l}
\varepsilon_{x x} \\
\varepsilon_{y y} \\
\varepsilon_{x y}
\end{array}\right\} \text { and } \vec{\sigma}=\left\{\begin{array}{l}
\sigma_{x x} \\
\sigma_{y y} \\
\sigma_{x y}
\end{array}\right\} \\
{[C] } & =\frac{1+y}{E}\left[\begin{array}{ccc}
1-v & -v & 0 \\
-v & 1-v & 0 \\
0 & 0 & 2
\end{array}\right]
\end{aligned}
$$

$$
\begin{gathered}
\vec{\sigma}=[D]\left(\vec{\varepsilon}-\overrightarrow{\varepsilon_{0}}\right)=[D] \vec{\varepsilon}-\frac{E}{1-2 v}\left\{\begin{array}{l}
1 \\
1 \\
0
\end{array}\right\} \\
{[D]=\frac{E}{(1+v)(1-2 v)}\left[\begin{array}{ccc}
1-v & v & 0 \\
v & 1-v & 0 \\
0 & 0 & \frac{1-2 v}{2}
\end{array}\right]}
\end{gathered}
$$

The component of stress in the $z$ direction will be nonzero and is given by:

and,

$$
\sigma_{x x}=v\left(\sigma_{x x}+\sigma_{y y}\right)-E
$$

$$
\sigma_{y x}=\sigma_{z x}=0
$$

Where $i$ represents the number of points at the continuous waler beam, $k$ is the higher order of the cubic function chosen for solving the problem and $\delta_{*}$ represent the displacement at the middle point of the continuous waler beam.

In order to recognize the optimum critical load that makes the waler at critical point, the cyclic load is divided into portions ranges from 0.1 to 1 , which represents the whole cyclic load acting on the sheet pile. [3]

Table (1) refers to the displacements at five nodes indicated at the critical section from the continuous waler beam with four spans specified. Six sets of cyclic load were applied on two types of sheet piles with $(30 \mathrm{~m})$ penetration depths. The five nodes where the displacements calculations were located on the top face of the back to back channel waler beam. See figure (3)

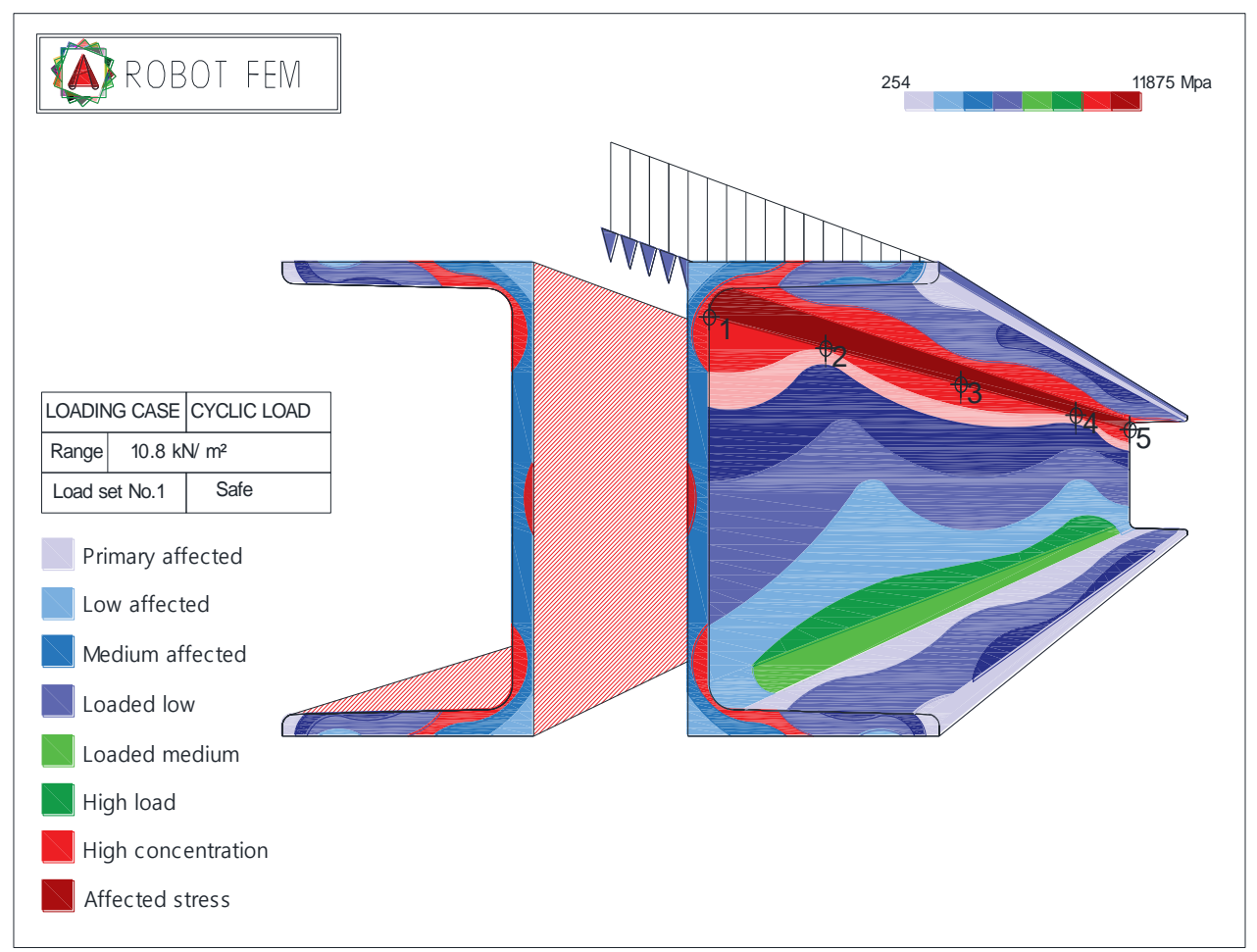

Figure (4) Reaction points on the waler 
Table (1) shows the cyclic load applied for set number one as an example for all the cyclic load applied. The behavior of the waler beam at the five nodes represents the displacements of the waler beam under the effect of applied cyclic load. Figure (4) shows the load displacement curves for six load cases applied on the walling beam.

Table (1) displacements calculation of waler beam under set 1 loading

\begin{tabular}{|c|c|c|c|c|c|c|c|c|}
\hline \multirow{2}{*}{$\begin{array}{l}\text { Set No. } \\
\text { Set } 1\end{array}$} & \multirow{2}{*}{$\begin{array}{c}\text { Cyclic load } \\
108.2 \\
\mathrm{kN} / \mathrm{m}^{2}\end{array}$} & \multicolumn{7}{|c|}{ Displacements measured in (mm) } \\
\hline & & & $\boldsymbol{\delta}_{1}$ & $\boldsymbol{\delta}_{2}$ & $\boldsymbol{\delta}_{3}$ & $\boldsymbol{\delta}_{4}$ & $\boldsymbol{\delta}_{5}$ & $\boldsymbol{\delta}_{*}$ \\
\hline \multirow[b]{2}{*}{1} & \multirow{2}{*}{10.8} & $+0.1 \mathrm{P}$ & 0.17 & 0.45 & 0.85 & 0.46 & 0.17 & \multirow[t]{2}{*}{0.86} \\
\hline & & $-0.1 \mathrm{P}$ & 0.15 & 0.43 & 0.87 & 0.44 & 0.16 & \\
\hline \multirow{3}{*}{2} & \multirow{3}{*}{21.6} & $+0.2 \mathrm{P}$ & 0.34 & 0.47 & 0.96 & 0.48 & 0.36 & \multirow[t]{3}{*}{0.95} \\
\hline & & & & & & & & \\
\hline & & & & & & & & \\
\hline \multirow[b]{2}{*}{3} & \multirow[b]{2}{*}{32.4} & $+0.3 \mathrm{P}$ & 0.85 & 0.95 & 1.25 & 0.94 & 0.84 & \multirow[t]{2}{*}{1.265} \\
\hline & & $-0.3 P$ & 0.91 & 0.94 & 1.28 & 0.95 & 0.93 & \\
\hline \multirow[b]{2}{*}{4} & \multirow{2}{*}{43.2} & $+0.4 \mathrm{P}$ & 1.22 & 1.45 & 1.64 & 1.46 & 1.23 & \multirow[t]{2}{*}{1.64} \\
\hline & & $-0.4 \mathrm{P}$ & 1.24 & 1.46 & 1.64 & 1.45 & 1.25 & \\
\hline \multirow[b]{2}{*}{5} & \multirow{2}{*}{54.1} & $+0.5 \mathrm{P}$ & 1.96 & 1.77 & 2.66 & 1.73 & 1.97 & \multirow[t]{2}{*}{2.673} \\
\hline & & $-0.5 \mathrm{P}$ & 2.00 & 1.76 & 2.69 & 1.71 & $\begin{array}{l}1.99 \\
\end{array}$ & \\
\hline \multirow[b]{2}{*}{6} & \multirow{2}{*}{64.9} & $+0.6 \mathrm{P}$ & 2.51 & 1.97 & 3.11 & 1.96 & 2.52 & \multirow[t]{2}{*}{3.12} \\
\hline & & $-0.6 \mathrm{P}$ & 2.54 & 196 & 3.13 & 1.97 & 254 & \\
\hline \multirow[b]{2}{*}{7} & \multirow[b]{2}{*}{75.7} & $+0.7 \mathrm{P}$ & 2.92 & 2.25 & 6.96 & 2.24 & 2.91 & \multirow[t]{2}{*}{6.95} \\
\hline & & 07 & 4 & 27 & 6 & 29 & 20 & \\
\hline & & & & & & & & \\
\hline \multirow[b]{2}{*}{8} & \multirow{2}{*}{86.5} & $+0.8 \mathrm{P}$ & 3.11 & 3.45 & 8.60 & 3.56 & 3.10 & \multirow[t]{2}{*}{8.61} \\
\hline & & $-0.8 \mathrm{P}$ & 3.11 & 3.89 & 8.62 & 3.65 & 3.91 & \\
\hline \multirow[b]{2}{*}{9} & \multirow[b]{2}{*}{97.3} & $+0.9 \mathrm{P}$ & 3.50 & 4.12 & 10.93 & 4.13 & 3.57 & \multirow[t]{2}{*}{10.95} \\
\hline & & $-09 \mathrm{P}$ & 355 & 433 & 1098 & 4 & 352 & \\
\hline \multirow{3}{*}{10} & \multirow{3}{*}{108.2} & $+P$ & 4.12 & 4.78 & 18.15 & 4.88 & 4.13 & 18.17 \\
\hline & & & & & & & & \\
\hline & & $-\mathrm{P}$ & 4.12 & 4.68 & 18.19 & 4.69 & 4.15 & \\
\hline
\end{tabular}




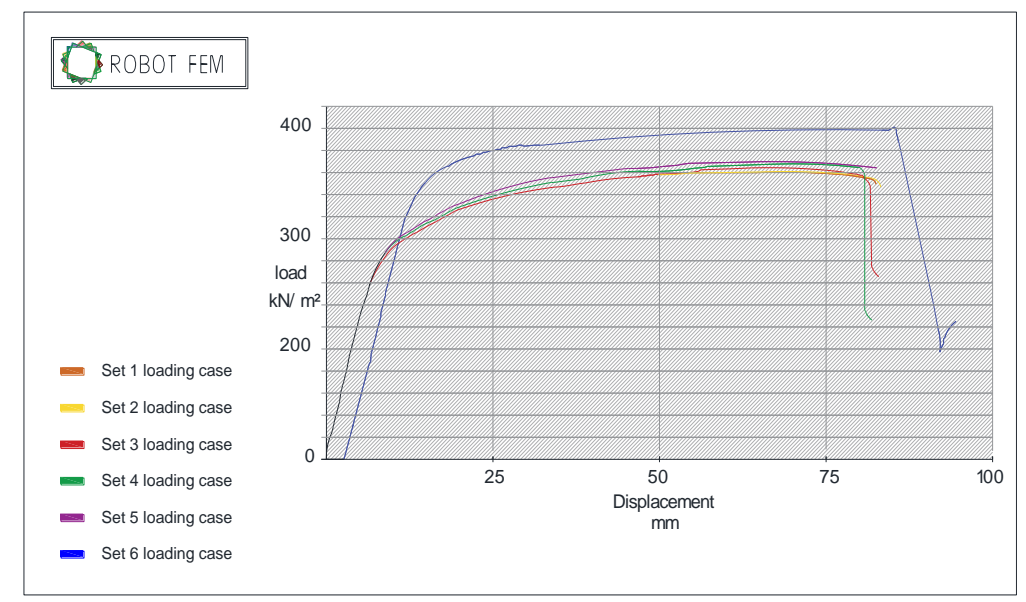

Figure (4) Load displacements curves for loading cases

\section{CONCLUSIONS}

The effect of using truss retaining system instead of tie rod and deadman system for long length berths could be more effective to withstand the cyclic load due to ships impact or sea waves. The use of a steel structure truss as retaining system decreases the probability of soil slip during excavation works. There are many factors that need to be considered in the analysis of the wailing like soil properties, sheet pile penetration depth, active and passive load pressure as well as the cyclic load effect then comparing the results.

\section{REFERENCES}

[1] John Wiley $5^{\text {th }}$ edition 2014 by I M Smith "Programming The Finite Element Method" University of Manchester U.K

[2] Singiresu S. Rao $4^{\text {th }}$ edition, 2004 “The Finite Element Method In Engineering” Elsevier Science \& Technology Books

[3] David V Hutton, $1^{\text {st }}$ edition 2004, "Fundamentals of Finite Element Analysis" Mc Graw Hill Higher Education

[4] David Baxter and others, 9 ${ }^{\text {th }}$ edition 2016 "Piling Handbook" ArcelorMittal Design \& Execution manual

[5] Wang Lun-yan, Qian Da-Xing, and Zhang Jianwe 2010, "Study on P-Y Curve Method for Computing Laterally Loaded Piles under Horizontal Distribution Loads" The International Conference on Computer Application and System Modeling, V5-366-369. 